\title{
CONSTRUÇÃO DE INDICADORES DE MENSURAÇÃO DO CAPITAL INTELECTUAL EM UMA EMPRESA BRASILEIRA DE CONSÓRCIOS
}

\section{CONSTRUCTION INDICATORS MEASUREMENT OF INTELLECTUAL CAPITAL IN BRAZILIAN COMPANY CONSORTIUM}

\author{
June Alisson Westarb Cruz ${ }^{1}$; Marilore Andrea Jaeger ${ }^{2}$; Luiz Eduardo Belletti ${ }^{3}$; Eliane de Oliveira ${ }^{4}$; \\ Carlos Olavo Quandt ${ }^{5}$ \\ ${ }^{1}$ Pontifícia Universidade Católica do Paraná \\ june.cruz@pucpr.br \\ ${ }^{2}$ Faculdade Cenecista de Campo Largo \\ marilore.jaeger@terra.com.br \\ ${ }^{3}$ SEBRAE-PR \\ lbelletti@pr.sebrae.com.br \\ ${ }^{4}$ UniCuritiba \\ elianedeoliveira@terra.com.br \\ ${ }^{5}$ Pontifícia Universidade Católica do Paraná \\ carlos.quandt@pucpr.br
}

\begin{abstract}
Resumo:
O contexto atual impõe às organizações a busca constante por vantagem competitiva, dentre outras possibilidades a mensuração e identificação do capital intelectual da empresa pode ser relacionado como uma interessante perspectiva de competição sob o aspecto estratégico. Nesse sentido o presente estudo tem por objetivo sugerir a construção de indicadores que possam refletir o esforço organizacional para o atingimento das metas estabelecidas e que potencializem o valor do conhecimento como recurso singular dentro da organização no ambiente competitivo. Nesse contexto a pesquisa, por meio de um estudo de caso em uma empresa brasileira de consórcios procura identificar e relacionar as principais diretrizes estratégicas da organização, seus principais indicadores para a operacionalização da implementação estratégica, sob o aspecto da mensuração de seu capital intelectual. Como resultado percebe-se a importante relação entre o capital intelectual e a abordagem estratégica da empresa diante de um mercado competitivo e intrigante.
\end{abstract}

Palavras-chave: capital intelectual; indicadores; estratégia; consórcios.

\section{Introdução}

Uma empresa baseada em conhecimento é uma organização de aprendizagem que reconhece o conhecimento como um recurso estratégico, e cria conhecimento que pode ser processado internamente e utilizado externamente, aproveitando o potencial de seu capital intelectual, em que o trabalhador do 
conhecimento é o componente crítico (GARVIN, 1993 apud PEREIRA, 2002).

Terra (2000 apud Pereira, 2002) identificou diferentes focos na literatura sobre a gestão do recurso "conhecimento" nas organizações. Entre estes focos, destacam-se questões como o aprendizado individual e organizacional; o desenvolvimento de competências individuais e organizacionais; o mapeamento, codificação e compartilhamento do conhecimento organizacional; a conectividade entre as pessoas; a alavancagem dos avanços na informática e em telecomunicações e a mensuração do capital intelectual da empresa.

A partir desses focos de estudo, Terra (1999 apud Pereira, 2002) desenvolveu um modelo de Gestão do Conhecimento baseado em sete dimensões da prática gerencial: (1) fatores estratégicos e o papel da alta administração: relacionamento da estratégia corporativa e o conhecimento organizacional; (2) culturas e valores organizacionais: avaliação do papel da cultura como fator facilitador ou barreira à criação e disseminação do conhecimento; (3) estrutura organizacional: análise do modelo de gestão mais adequado às práticas da gestão do conhecimento; (4) administração de recursos humanos: análise das políticas de gestão de pessoas que orientarão as práticas de gestão do conhecimento; (5) sistemas de informação: avaliação das bases de dados da empresa, incluindo a tecnologia da informação, visando transformá-las em informação e esta em conhecimento; (6) mensuração de resultados: desenvolvimento de metodologias de avaliação de resultados estratégicos e 3 operacionais, visando dimensionar, entre outros aspectos, os ativos intangíveis relacionados ao conhecimento organizacional; (7) aprendizado com o ambiente: análise do conhecimento acumulado a partir de experiências desenvolvidas na cadeia de valor ou no ambiente de negócio da empresa.

$\mathrm{O}$ presente artigo tem por objetivo construir indicadores que possam refletir o esforço organizacional para o alcance das metas estabelecidas e que potencializem o valor do conhecimento como recurso singular dentro da organização. Para isso, foi selecionada uma das 10 maiores empresas brasileiras de consórcios como alvo de um estudo mais aprofundado, onde são identificadas suas principais diretrizes estratégicas, que constituem o ponto de partida deste estudo para a construção de indicadores que mensurem a implementação estratégica e a medição de capital intelectual.

\section{Revisão literatura}

\subsection{Conhecimento}

Observa-se que as inovações tecnológicas, cada vez mais acessíveis a todos os setores econômicos, reduziram a distância diferenciadora entre as empresas, que passaram a ter possibilidade de acesso a novidades e evoluções surgidas em qualquer parte do mundo. $\mathrm{O}$ diferencial entre as 
empresas não é mais o uso intensivo de máquinas utilizadas no processo produtivo, mas sim o somatório do conhecimento coletivo gerado e adquirido, as habilidades criativas e inventivas, os valores, atitudes e motivação das pessoas que as integram e o grau de satisfação dos clientes. São os chamados ativos intangíveis, os conhecimentos tácitos ou explícitos que geram valor econômico para a empresa e cuja origem está diretamente relacionada aos agentes criativos da empresa.

Atualmente, as empresas têm feito grande uso da tecnologia da informação como instrumento gerencial. Estas informações são utilizadas para repor estoques, abastecer depósitos e outros ativos físicos, economizando tempo e como dinheiro. Administrar o conhecimento como faturas, mensagens, patentes, processos, habilidade dos funcionários, conhecimento dos clientes, fazendo uso intensivo de máquinas, computadores, para tal, determina o sucesso ou fracasso da empresa nos tempos de hoje.

Nesta "sociedade do conhecimento", aos três fatores tradicionais de produção (recursos naturais, mão-de-obra e capital) acrescenta-se o conhecimento e a inteligência das pessoas, agregando valor aos produtos e serviços. Como argumenta Drucker (1996), o conhecimento passou a ser o recurso, ao invés de um recurso. "O valor não esta na informação armazenada, mas na criação de conhecimento de que ela pode fazer parte" (SVEIBY, 1998).

\subsection{Capital intelectual}

A informação e o conhecimento são as armas competitivas de nossa era. São mais valiosos e poderosos que recursos naturais, grandes indústrias ou vultosas contas bancárias. Em todos os setores, as empresas bem-sucedidas são as que têm as melhores informações (em tempo ágil e com boa qualidade) e que sabem usá-las de forma eficaz. A Microsoft e o Yahoo, por exemplo, não se tornaram grandes empresas por serem mais ricas que a IBM ou a Ford. É exatamente o contrário: elas tinham algo mais valioso que recursos físicos ou financeiros - o capital intelectual.

O capital intelectual passou a ser tratado com maior interesse nos meios empresariais e acadêmicos a partir do início da década de oitenta, em função de diversos estudos desenvolvidos na área. Vianna (1998), relata que o capital intelectual busca observar o conjunto de ativos intangíveis de um empresa, sendo ativos decisivos no desempenho da empresa que no entanto não são considerados pela contabilidade, sendo tão importante que em alguns casos supera o valor dos capitais tangíveis da empresa. Edvinsson e Malone (1998), sugerem que o capital intelectual pode ser uma nova teoria, e na prática apresenta-se há muito tempo, entre o valor de mercado e o valor contábil apresentados as empresas. Stewart (1998), afirma que é o capital intelectual (que constitui a soma do conhecimento de todos os colaboradores de uma empresa), o que lhe proporciona vantagem competitiva. Ao contrário da 
maioria dos ativos, com os quais os empresários e contabilistas estão familiarizados - propriedade, fábricas, equipamento, dinheiro - o capital intelectual é intangível.

Stewart (1998), acrescenta que o capital intelectual esta na relação entre os capitais humano, estrutural e de clientes, não podendo ser tratado em partes distintas. Sendo assim, o capital intelectual pode ser dividido em três grandes capitais. O capital humano, o capital estrutural e o capital do cliente são todos intangíveis mas descrevem resultados tangíveis para os executivos. É a interação entre eles que cria o capital intelectual.

\subsubsection{Capital humano}

Constituem o capital humano: o conhecimento acumulado, a habilidade e experiências dos funcionários para realizar as tarefas do dia-a-dia, os valores, a cultura, a filosofia da empresa, e diversos ativos intangíveis, ou seja, as pessoas que são os ativos humanos da empresa. A principal estratégia da empresa será de atrair, reter, desenvolver e aproveitar ao máximo o talento humano, que será cada vez mais, a principal vantagem competitiva. O capital humano é aquele incorporado nas pessoas que possuem talentos para criação de produtos e serviços de qualidade, com o intuito de atrair clientes e satisfazê-los da melhor maneira possível. Talento é a essência da pessoa, o que compreende seus pensamentos e sentimentos. Conhecimento e habilidades podem ser ensinados, transferidos de uma pessoa para outra; talento é o próprio estilo da pessoa, e não pode ser transferido para outro. A grande chave do sucesso de uma empresa é ajudar seus funcionários a conduzirem seus talentos na busca de um excelente desempenho.

Fazer a diferenciação entre os funcionários é necessário para orientar corretamente o investimento em treinamentos e formação, visando o retorno em forma de atitudes, pois quanto mais motivados e interessados os colaboradores, mais se sentem parte da empresa. Percebe-se então a disposição desses colaboradores em participar, oferecer novas idéias e aprender novas tarefas. Assim, Straioto (2000) considera que o capital humano é um recurso empresarial e deve ser considerado um ativo, pois possui capacidade de gerar benefícios futuros para a empresa.

\subsubsection{Capital estrutural}

Segundo Stewart (1998) o capital estrutural pertence à empresa como um todo, podendo ser reproduzido e dividido. Compreende os ativos intangíveis relacionados com a estrutura e os processos de funcionamento interno e externo da organização que apóiam o capital humano, ou, tudo o que permanece na empresa quando os empregados retornam para suas casas. Este capital refere-se ao 
conhecimento contido e retido, o conhecimento de propriedade da empresa, e incluem dados, tecnologias, estrutura e sistemas, rotinas e procedimentos organizacionais. A infra-estrutura que apóia o capital humano, como equipamentos de informática, softwares, bancos de dados, também forma o capital estrutural.

Stewart (1998) afirma que os motivos para gerenciamento do capital estrutural consistem no alcance de uma rápida distribuição de conhecimento, aumentando o conhecimento coletivo, menores tempos de espera e desempenho de profissionais mais produtivos. Edwinsson e Malone (1998), apresentam uma forma de organizar o capital estrutural, sendo ela em: (1) organizacional; (2) inovação; (3) e de processos. O capital organizacional abrange os investimentos em sistemas, instrumentos e filosofia operacional que visa agilizar o fluxo de conhecimentos pela empresa em seu âmbito interno e externo.

\subsubsection{Capital de clientes}

Stewart (1998) diz que o capital do cliente é muito semelhante ao capital humano: não se pode possuir os clientes do mesmo modo como não se pode possuir pessoas. Mas da mesma forma como uma organização pode investir em funcionários não apenas para aumentar seu valor como indivíduos mas também para criar ativos de conhecimento para a empresa como um todo, a empresa e seus clientes podem aumentar o capital intelectual que é sua propriedade em conjunto e em particular.

Para investir no capital do cliente, deve-se analisar alguns fatores, tais como: inovar com os clientes; concentrar-se nos clientes como indivíduos, atendendo às necessidades dos clientes individuais; dividir os ganhos com os clientes; conhecer o negócio do cliente para melhor servi-lo e tornar-se indispensável.

\subsubsection{A mensuração do capital intelectual}

Mesmo sendo considerado um ativo intangível, o capital intelectual pode ser mensurado. Esta mensuração irá complementar e enriquecer a contabilidade, fazendo com que alcance o seu papel de fornecer informações úteis da melhor maneira possível, já que a contabilidade necessita de demonstrações contábeis com informações atuais de natureza intelectual humana, ecológica e social.

As avaliações dos ativos intangíveis são feitas para atender as necessidades de atendimento dos clientes, credores e acionistas ou para uso dos gestores da empresa. Para avaliar os ativos intangíveis, o processo é o seguinte: determinação da finalidade: uso externo e/ou interno; a classificação dos funcionários dentro de uma das três categorias de ativos intangíveis, que são: competência, estrutura 
interna e estrutura externa; a formulação de uma estratégia para gestão do conhecimento; informações que deverão enfatizar o fluxo, a mudança e os dados de controle; comparação dos indicadores em relação aos anos anteriores; apresentação dos indicadores num quadro denominado de Monitor de Ativos intangíveis.

\section{Metodologia da pesquisa}

Para confecção deste artigo, optou-se por uma análise mais detalhada e profunda de uma única organização, caracterizando um estudo de caso. Baseou-se na investigação da Unidade de Negócios de Curitiba de uma grande empresa brasileira de consórcios durante o período de Janeiro de 2004 a Maio de 2006, fase em que ocorreu uma importante mudança estratégica na referida empresa.

A investigação do estudo de caso defronta uma situação na qual haverá mais variáveis de interesse do que fontes de dados. Dessa forma, baseia-se em fontes de evidências. Também se beneficia do desenvolvimento de proposições teóricas para realizar a coleta e a análise de dados (YIN, 2005).

Para a coleta de dados, foram realizadas entrevistas semi-estruturadas, direcionadas aos níveis tático e estratégico da organização pesquisada, totalizando três entrevistas, com a duração média de trinta minutos cada. A seleção do nível estratégico para a pesquisa ocorreu em função da responsabilidade da formulação, condução e implementação das estratégias e do nível tático para ajudar a interpretar a percepção e absorção das novas estratégias. Foram disponibilizados alguns documentos e relatórios formais que demonstraram a evolução da operação nos últimos 20 meses.

Durante a entrevista foram abordados temas relacionados ao Planejamento Estratégico, as metas atuais e pretendidas e de que forma os principais gestores obtinham informações que permitiam mensurar a implementação da estratégia.

\section{Apresentação e análise dos dados}

\subsection{Apresentação dos dados}

De acordo com o Banco Central (2005), as operações de consórcio tiveram origem no Brasil no início dos anos sessenta, em razão da carência de instituições financeiras empenhadas na concessão de financiamentos à aquisição de bens, aliada à necessidade das indústrias recentemente instaladas escoarem sua produção.

Com o passar dos anos, o sistema estabeleceu-se definitivamente, fortemente regulamentado pelo Banco Central, o setor amadureceu e ganhou a simpatia dos Bancos que ingressaram recentemente no mercado. Os dados do Banco Central (2005) apontam a existência de pouco mais de 340 
administradoras de consórcios ativas, sendo este setor responsável por uma expressiva movimentação de capital de cerca de 3,3 milhões de clientes ativos, (BANCO CENTRAL, 2005).

De acordo com o Banco Central (2005), a redução de players nos últimos anos é uma conseqüência da forte regulamentação exercida sobre o setor aliada à tendência de incorporações e fusões. Constatou-se, entretanto, um aumento de número de clientes ativos no mesmo período.

O contexto atual do setor de consórcios demonstra retração de competidores e aumento de captação de clientes, o que impulsiona as organizações buscarem criar diferenciais a partir de seus recursos e competências. Para Hofer e Schendel (1978 apud Coletta, 2003) uma empresa possui um perfil que combina recursos e habilidades, necessários ao desenvolvimento de sua vantagem competitiva.

Criada em 1988, a administradora de consórcios objeto do estudo, possui sua sede em São Paulo, e solidificou sua posição estratégica após ter desenvolvido competências singulares na administração e vendas de grupos de consórcio para um público-alvo específico, voltado ao segmento de motocicletas e veículos populares.

O Planejamento Estratégico formalizado pela empresa enfatiza 9 diretrizes amplas que norteiam todas as suas operações. Um de seus principais gestores explica qual a compreensão por 'Diretrizes' para a organização: "são definições que norteiam e delimitam as ações estratégicas da empresa, as quais, normalmente, não mudam ao longo de sua existência e devem atender à missão e valores declarados pela mesma."

A seguir, destaca-se o foco central de cada diretriz a ser alcançada: (1) Crescimento: o crescimento deve considerar sempre o conjunto da ampliação de sua carteira futura, assim como de seu lucro. Portanto, a medida de seu crescimento será o valor agregado de $50 \%$ de sua receita (taxa) futura mais o lucro obtido no período; (2) Caixa: o caixa é para seu uso exclusivo e deve chegar a um nível mínimo igual ao seu passivo através de uma distribuição de sua sobra (superávit, depois de pagas as despesas de custeio): 65,5\% reservas; 14\% melhoria contínua; $12 \%$ aquisição de cotas e reformas; 4,5\% PPRC; 2,5\% educação; 1,5\% qualidade de vida e projetos sociais; (3) Patrimônio: a preservação do patrimônio dos acionistas e a busca da perpetuação da empresa é a prioridade máxima a ser perseguida, e, portanto, nenhuma ação ou novo produto poderá apresentar TIR ou Rentabilidade que ponha em risco este equilíbrio; (4) Mercado: dirigir todas as ações e buscar soluções que permitam, gradativamente, a redução da taxa de administração, sem prejuízo ao encantamento dos clientes e rentabilidade, até que seja possível manter o nível mais baixo do mercado em todos os segmentos; (5) Orçamento: a principal ferramenta de controle é o orçamento e o seu cumprimento é a prioridade de todos, sendo que as Unidades devem cumpri-lo, independentemente de gerarem resultados gerenciais 
positivos; (6) Cliente Externo: os Clientes são a razão de ser da administradora e, para encantá-los, toda ação ou projeto deverá contemplá-los e/ou gerar algum valor agregado a eles, exceção feita aos projetos dirigidos aos colaboradores da empresa; (7) Cliente Interno: os recursos humanos se constituem como patrimônio, por isso, deverão apresentar um crescimento sustentável, que permita agregar um aumento real na remuneração anual, de forma a garantir a retenção de talentos; (8) Qualidade: o sucesso vem da qualidade dos serviços, domínio da informação, atualização dos colaboradores e da inovação das tecnologias, produtos e ferramentas; (9) Vendas: o modelo para comercialização de produtos deve ter sempre como linha básica potencializar o vendedor e o parceiro para alavancar o crescimento da carteira, priorizando os modelos que já apresentam sucesso.

\subsection{Análise dos dados}

Mediante a compreensão das diretrizes e metas definidas pela empresa estudada, este estudo criou indicadores específicos para sua mensuração e foram dispostos aos gestores para avaliação da sua importância e pertinência à operação, conforme Quadro 1 abaixo.

Quadro 1: Indicadores sugeridos

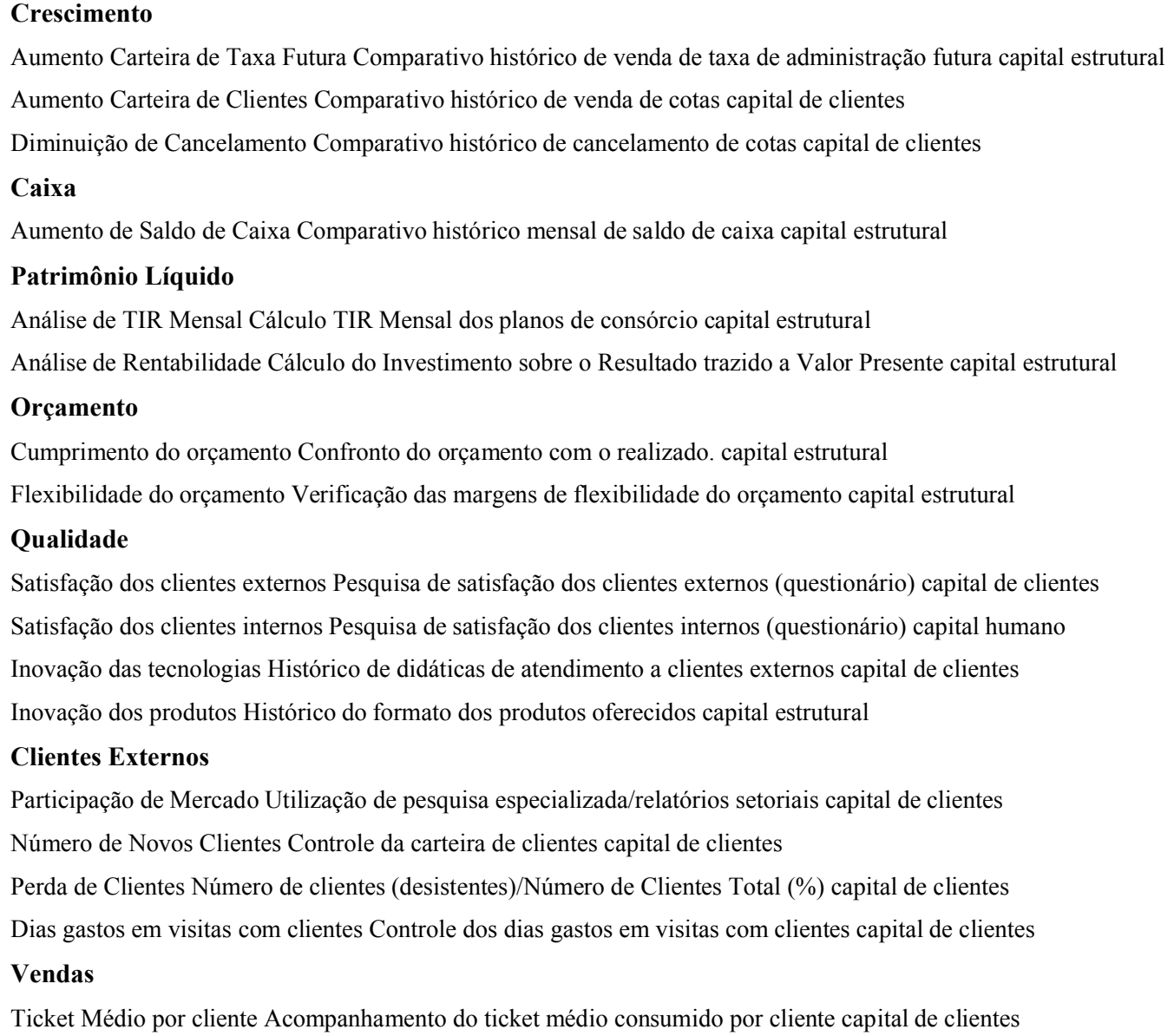




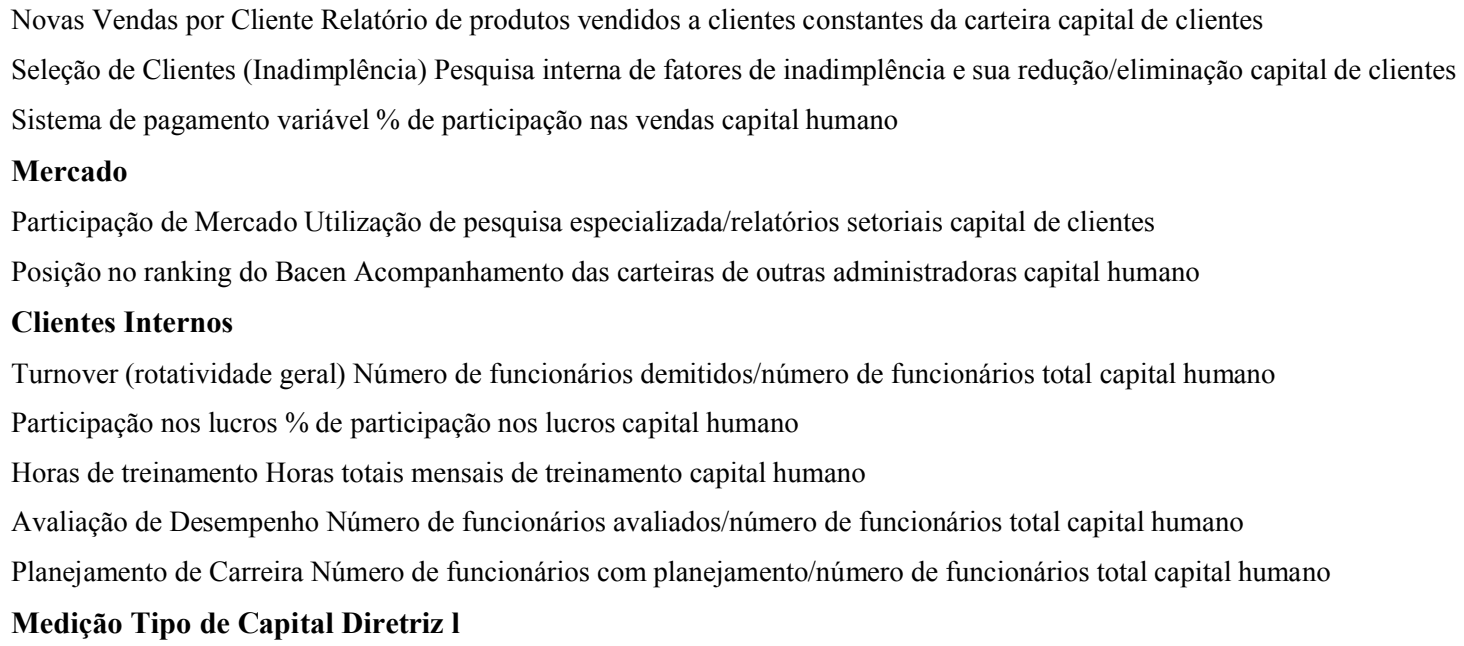

A diretriz de Crescimento, preocupa-se claramente com a ampliação da carteira futura, ou seja, o aumento da carteira de clientes impacta diretamente no recebimento futuro da taxa de administração vendida. Para observar o atingimento da meta estabelecida, um indicador sugerido é a evolução histórica de taxa futura vendida. A comparação da venda de taxa com os meses anteriores demonstra a proporção de crescimento que está sendo obtida, e permite ainda traçar tendências quanto a política de atuação em vigência. Outro indicador refere-se à evolução de quantidade de cotas vendidas que permite avaliar comparativamente aos meses anteriores em qual segmento há maior concentração de vendas, se há correspondência às expectativas ou se é preciso efetuar alguma ação para atingir os segmentos desejados. Para avaliação do crescimento, ainda é preciso considerar índices de cancelamento de vendas e compará-los historicamente. Os indicadores sugeridos para esta diretriz são extraídos diretamente do sistema de gestão de consórcios, podendo ser coletado a qualquer instante.

O indicador sugerido para a diretriz Caixa, considera uma análise histórica dos saldos de caixa como comparativo de seu desempenho. A meta estabelecida é de obtenção de aumento do saldo e imprescindivelmente manter-se ao nível mínimo igual ao seu passivo.Este indicador pode ser obtido através do sistema de gestão. Com relação à diretriz Patrimônio Líquido, foram sugeridos dois indicadores sendo que o primeiro avalia a TIR (Taxa Interna de Retorno) dos planos consorciais, ou seja, cada grupo de consórcio deve apresentar uma TIR superior ao mínimo estabelecido. E o segundo indicador avalia a rentabilidade da operação através da mensuração do resultado trazido a valor presente pelo investimento realizado. Para cálculo de ambos indicadores, os dados podem ser obtidos através do sistema de gestão.

A diretriz Orçamento será mensurada também através do sistema de gestão. Embora o primeiro indicador permita observar a capacidade de previsão de despesas e realizações de cada unidade, é razoável admitir que variações macroeconômicas influenciem os resultados que ocorrem meses depois 
do orçamento. Assim, o orçamento deve possuir alguma flexibilidade (a ser verificado no segundo indicador desta diretriz), porém sem perder de vista a diretriz estratégica que lhe deu origem.

A Qualidade é a única diretriz da empresa que envolve diretamente todos os segmentos do Capital Intelectual, possuindo indicadores para o Capital Humano, Estrutural e de Clientes. A atualização dos colaboradores, que impacta diretamente na qualidade percebida pelos clientes e a satisfação com seu trabalho, são dois indicadores para o Capital Humano percebido nesta diretriz. A satisfação dos clientes da administradora de consórcio, bem como o uso de inovação em tecnologia, indicam a percepção dos clientes em relação aos serviços e produtos da empresa e auxiliam na mensuração da qualidade percebida. São claramente indicadores de qualidade classificados como Capital do Cliente. Por fim, a inovação a ser mensurada nos produtos indica como a qualidade está sendo buscada no desenvolvimento de soluções e a utilização de métodos, estruturas e conhecimentos pré-existentes ou adquiridos para este propósito, que refletem a condição do Capital Estrutural sobre esta diretriz.

A diretriz estratégica Clientes Externos foca o cliente da organização, que é ao final, a razão da existência desta. Alguns indicadores como Número de Novos Clientes e Perda de Clientes poderão ser obtidos diretamente do sistema de gestão, havendo porém a necessidade de se estudar criteriosamente os motivos que levam a esta movimentação, no esforço de se maximizar o primeiro resultado e minimizar o segundo. Outros estudos, como os relatórios emitidos pelo Bacen, auxiliam a mensuração e avaliação do indicador Participação do Mercado. Este indicador é fundamental para que durante o Planejamento Estratégico sejam definidas metas para o próximo exercício. Além destes, alguns indicadores de esforço como os Dias Gastos em Visitas a clientes são úteis ao desenvolvimento de novas técnicas de captação de clientes. O indicador Grau de Satisfação do Cliente permite um acompanhamento mensal da percepção dos clientes e conseqüentes correções de rumo que se façam necessárias.

Em relação às Vendas, os indicadores sugeridos passam por soluções eficazes na alavancagem das vendas da empresa. A mensuração do Ticket Médio por cliente, permitirá tanto o desenvolvimento de produtos adequados a cada segmento atendido, bem como a definição de metas a serem alcançadas pelos vendedores. Associado a este indicador, a Seleção de Clientes observando-se a inadimplência permitirá uma melhoria na qualidade das vendas. Se observados estes critérios, houver uma seleção criteriosa de clientes que além de pagar em dia, podem e desejam pagar mais por produtos de "primeira linha" o conceito de volume de clientes passará gradativamente a ser substituído pelo conceito de clientes de qualidade. O cliente de consórcio é potencial cliente de um novo consórcio, pois já conhece os benefícios do sistema, já possui um valor mensal alocado para a aquisição de um bem e confia na 
instituição. Nada mais natural do que oferecer aos próprios clientes novos produtos e serviços. Um relatório indicador de percentual variável sobre as vendas pode indicar a efetividade do modelo, bem como quais os colaboradores que são mais incentivados por ele.

Em relação ao Mercado foram definidos dois indicadores que, embora semelhantes, guardam diferenças significativas na sua coleta e representam resultados diferentes alinhados à estratégia de crescimento e participação no mercado de consórcios brasileiro. A Participação de Mercado deve focar o crescimento do mercado e a participação da empresa neste crescimento. Já a Posição do Ranking do Bacen alinha-se com a estratégia da empresa em situar-se entre as 10 maiores administradoras do país. A partir da posição no ranking é possível determinar cases de estudo para conhecer estratégias de crescimento adotadas pelos concorrentes (benchmarking) e o aparecimento de novos players ou players não tradicionais (como a entrada de empresas internacionais, no mercado brasileiro, por exemplo). Abaixo vemos o quadro extraído do site do Banco Central na Internet que pode ser utilizado para a análise deste indicador.

Já a análise dos indicadores de Clientes Internos demonstra claramente a preocupação em traduzir os esforços das equipes em resultados para a empresa. A busca pela diminuição do Turnover e o aumento na quantidade e qualidade de horas de treinamento associados a uma política mensurável de Avaliação do Desempenho e Planejamento de Carreira oferecem tranqüilidade e senso de respeito profissional e preocupação com o público interno, que acaba por refletir em diretrizes observadas anteriormente (vendas e qualidade, por exemplo). A estruturação do indicador de Participação nos Lucros exige pouco esforço, pois suas informações serão retiradas do sistema de gestão, mas propicia elevado senso de responsabilidade pelos resultados e comprometimento com as metas da empresa.

A implementação de instrumentos de gestão sobre cada um dos indicadores propostos passa pelo revisão de relatórios existentes na empresa, desenvolvimento de novos relatórios e pela consulta sistemática a informações baseadas no Banco Central.

\section{Considerações finais}

Após a elaboração e justificativa de cada indicador, a Tabela 2 - Indicadores Sugeridos, que contém os indicadores relativos à mensuração do Capital Intelectual da organização foi submetida aos respondentes das entrevistas que julgaram os indicadores pertinentes e úteis para tomada de decisão e para o redirecionamento das diretrizes que ocorre anualmente durante o planejamento estratégico. Porém, sugeriram que podem ser indicadores difíceis de serem mensurados mais pela falta de cultura da empresa em medir intangíveis, do que exatamente a dificuldade operacional que cada um deles 
pressupõe. Por tratar-se de empresa de porte nacional, a aplicação dos conceitos passaria necessariamente por discussão em várias instâncias para ser implementada. $O$ indicador Acompanhamento do Ticket Médio por Cliente foi considerado desnecessário pois, embora reflita uma estratégia útil, não está contemplada no atual posicionamento estratégico da empresa. Na Tabela 4 Aspectos do Capital Intelectual em cada diretriz estratégica da empresa pode-se ainda observar que a distribuição do Capital Intelectual pelas diretrizes indica que o planejamento estratégico da empresa em questão ou o ramo de consórcios no Brasil como um todo é equilibrado, não dependendo exclusivamente de um ou outro aspecto componente.

Estudos futuros podem aprofundar a questão procurando identificar padrões nas empresas participantes deste mercado. Durante o levantamento dos dados pôde-se observar que a elaboração de indicadores de mensuração do Capital Intelectual passa obrigatoriamente pelo alinhamento com as estratégias e diretrizes da empresa. Stewart (1998) chama a atenção para o fato de que o relacionamento com clientes, a estrutura da organização e o elemento humano só passam a ser considerados capital intelectual quando são sistematicamente observados, contribuem com a estratégia da empresa e por extensão, geram resultados. Em outras palavras, passam a ser ativos (ainda que intangíveis) na melhor definição contábil para o termo, podendo ser revertidos em resultados financeiros, vantagens presentes ou futuras ou benefícios competitivos para a empresa.

Observou-se que o segmento de consórcios no Brasil é intensivo em informação e que a sua coleta, tratamento e utilização são fatores essenciais à sustentabilidade e competitividade das empresas. Ainda que o ambiente possa ser classificado como relativamente estável, devido a forte regulação da atividade em nosso país e o acompanhamento próximo do Banco Central, as comuns oscilações dos indicadores econômicos (dólar, inflação, juros e comportamento do consumidor, por exemplo) podem causar instabilidade no setor. $\mathrm{O}$ acompanhamento constante destas oscilações e a capacidade de análise e resposta da organização, mobilizando seus ativos intangíveis, são fatores determinantes para o atingimento e superação de suas metas.

\footnotetext{
Abstract

The current context requires organizations to the constant search for competitive advantage, among other possibilities to measure and identify the intellectual capital of the company can be listed as an interesting perspective of competition under the strategic aspect. In this sense the present study aims to suggest the construction of indicators that can reflect the organizational effort to accomplish the goals and leverage the value of knowledge as a unique resource within the organization in the competitive environment. In this context the research through a case study in a Brazilian consortium seeks to identify and relate the main strategic guidelines of the organization, its main indicators for the deployment of strategic deployment, under the aspect of measuring intellectual capital. As a result we see the important relationship between intellectual capital and strategic approach the company on a competitive market and intriguing.
} 
Key-words: intellectual capital; indicators; strategy; consortia.

\section{Referências}

ASSOCIAÇÃO BRASILEIRA DOS ADMINISTRADORES DE CONSÓRCIO (ABAC). Citações. Disponível em: < http://www.abac.org.br >. Acesso em: 18 dez. 2005.

ALMEIDA, M. G. M., HAJJ, Z. S. Mensuração e Avaliação do Ativo: uma revisão conceitual e uma abordagem do goodwill e do ativo intelectual. Caderno de Estudos. São Paulo, FIPECAFI, v. 9, n. 16, jul/dez 1997.

ANAND, V.; GLICK, W. H.; MANZ, C. C. Capital social: explorando a rede de relações da empresa. Revista de Administração de Empresas, v.42, n.4, p. 57-73, out./nov./dez. 2002.

Banco Central. Consórcios - Estatísticas de novembro de 2005. Disponível em: $<$ http:/www.bacen.gov.br/FIS/Consorcios/Port/est2005/11/default.asp?ano=2005\&mes=11\&id=consest200511 $>$. Acesso em: 21 dez. 2005.

COLETTA, A. O conhecimento como recurso estratégico na criação da vantagem competitiva da empresa: estudo de caso na empresa COPEL Geração S.A. Curitiba, 2003. 170 f. Dissertação (Mestrado em Administração) - Centro de Ciências Sociais Aplicadas, Pontifícia Universidade Católica do Paraná.

DRUCKER, P. F. Sociedade pós-capitalista. 5.ed. são Paulo: Pioneira, 1996

EDWINSSON, L.; MALONE, M. S. Capital Intelectual: descobrindo o valor real de sua empresa pela identificação de seus valores internos. Tradução de Roberto Galman. São Paulo: Makron Books, 1998.

FLEURY, M. T. L.; OLIVEIRA JUNIOR, M. de M. Gestão estratégica do conhecimento: integrando aprendizagem, conhecimento e competências. São Paulo: Atlas, 2001.

GIL, A. C. Métodos e técnicas de pesquisa social. 5. ed. São Paulo: Atlas, 1999.

GODOY, A . S. Pesquisa qualitativa: tipos fundamentais. Revista de Administração de Empresas, v. 35, n. 3, p. 20-29, mai/jun. 1995.

KLEIN, D. A gestão estratégica do capital intelectual: recursos para a economia baseada no conhecimento. Rio de Janeiro: Qualitymark, 1998.

NONAKA, I.; TAKEUCHI, H. Criação de conhecimento na empresa: como as empresas japonesas geram a dinâmica da inovação. 7. ed. Rio de Janeiro: Campus, 1997.

MARTINS, E. Contribuição à Avaliação do Ativo Intangível. São Paulo, 1972. (Tese de Doutorado) - FEA/USP.

PADOVEZE, C. L. Aspectos da gestão econômica do capital humano. Revista de Contabilidade do Conselho Regional de Contabilidade de São Paulo. São Paulo - SP: ano IV, nº 14, p.4-20, dez/2000.

PAIVA, S. B. O capital intelectual e a contabilidade: o grande desafio no alvorecer do $3^{\circ}$ milênio. Revista Brasileira de Contabilidade. Brasília - DF: ano 28, nº 117, p.76-82, mai/jun.1999.

PEREIRA, H. Modelo de gestão para organizações baseadas no conhecimento. In: SIMPÓSIO DE GESTÃO DA INOVAÇÃO TECNOLÓGICA, 2002, Salvador. Anais... XXII Simpósio de Gestão da Inovação Tecnológica. Salvador: Fundação Instituto de Administração da USP, 2002.

PIETROVSKI, E. F. A gestão do conhecimento e a cooperação Universidade-Empresa: o caso da unidade de Ponta Grossa do CEFET-PR. Florianópolis, 2002. 147 f. Dissertação (Mestrado em Engenharia da Produção) - Programa de PósGraduação, Universidade Federal de Santa Catarina . 
QUANDT, C. O. et al. A Produção Científica Brasileira em Gestão do Conhecimento: Análise Cienciométrica e Mapeamento de Redes de Autores do ENEGEP, 1998-2008. Revista Gestão Industrial, v. 05, p. 172-188, 2009.

RESENDE, E. O Livro das competências: a melhor ajuda para as pessoas, organizações e sociedade. Rio de Janeiro: Qualitymark, 2001.

STEWART, T. A. Capital intelectual: a nova vantagem competitiva das empresas. 11. ed. Rio de Janeiro: Campus, 1998.

SVEIBY, E. K. A nova riqueza das organizações: gerenciando e avaliando patrimônios do conhecimento. Rio de Janeiro: Campus, 1998.

TERRA, J. C. C. Os desafios da produtividade: novas habilidades na era da informação e do conhecimento e o papel central da gestão do conhecimento. Disponível em:

http://www.cgee.org.br/cncti3/Documentos/Seminariosartigos/Inclusaosocial/DrJose\%20Claudio\%20Cyrineu\%20Terra.pdf >. Acesso em: 22 dez. 2005.

VIANNA, M. A. F. Admirável Mundo Novo. Em ser humano. São Paulo, v. 32, n. 35, ago. 1998.

Nome completo: June Alisson Westarb Cruz

Filiação institucional: PUCPR

Departamento: CCSA

Função ou cargo ocupado: Professor

Endereço completo para correspondência (bairro, cidade, estado, país e CEP): Rua João GAva, 78 -

São Lourenço - Curitiba - Paraná - Cep.: 82130-010

Telefones para contato: 41-96150089 41-96150089

e-mail:june.cruz@pucpr.br

Nome completo: Marilore Andrea Jaeger

Filiação institucional: Faculdade Cenecista de Campo Largo

Departamento: Administração

Função ou cargo ocupado: Professora

Endereço completo para correspondência (bairro, cidade, estado, país e CEP): Rua João GAva, 78 -

São Lourenço - Curitiba - Paraná - Cep.: 82130-010

Telefones para contato: 41-96150089

41-96150089

e-mail:marilore.jaeger@terra.com.br

Nome completo: Luiz Eduardo Belletti

Filiação institucional: Sebrae-Pr

Departamento: Administração

Função ou cargo ocupado: Administrador 
Endereço completo para correspondência (bairro, cidade, estado, país e CEP): Rua João GAva, 78 São Lourenço - Curitiba - Paraná - Cep.: 82130-010

Telefones para contato: 41-96150089

41-96150089

e-mail:lbelletti@pr.sebrae.com.br

Nome completo: Eliane de Oliveira

Filiação institucional: UniCuritiba

Departamento: Administração

Função ou cargo ocupado: Professora

Endereço completo para correspondência (bairro, cidade, estado, país e CEP): Rua João GAva, 78 São Lourenço - Curitiba - Paraná - Cep.: 82130-010

Telefones para contato: 41-96150089 41-96150089

e-mail:elianedeoliveira@terra.com.br

\section{Nome completo: Carlos Olavo Quandt}

Filiação institucional: PUCPR

Departamento: CCSA

Função ou cargo ocupado: Professor

Endereço completo para correspondência (bairro, cidade, estado, país e CEP): Rua Imaculada Conceição, 950 - Prado Velho - Curitiba - Paraná

Telefones para contato: $8408-5764$

e-mail: carlos.quandt@pucpr.br

Enviado em: 06/02/2010

Aprovado em: 04/03/2011 